\title{
Breve historia del movimiento de la hermenéutica analógica (1993-2003)
}

\author{
NAPOLEÓn CONDE GAXIOLA \\ Escuela de Pedagogía \\ Universidad Intercontinental \\ Napoleon_conde@yahoo.com.mx
}

\begin{abstract}
Resumen: Este artículo reseña el movimiento surgido en torno a la propuesta del filósofo mexicano Mauricio Beuchot, llamada hermenéutica analógica. Se presenta, en primer lugar, un resumen de la propuesta del propio Beuchot, y en seguida se plantean algunos de los avances de otros investigadores, entre ellos, los de Samuel Arriarán (hermenéutica analógico-barroca) y Luis Álvarez Colín (hermenéutica simbólico-analógica), que son ya propuestas propias. También se hace referencia a algunas aplicaciones de la misma hermenéutica analógica en diversos campos, como en la pedagogía, la psicología y la literatura.
\end{abstract}

Palabras clave: filosofía en México, interpretación, iconicidad, símbolo

\begin{abstract}
This article offers an overview of the philosophical movement originated around the proposal of the Mexican philosopher Mauricio Beuchot, named Analogic Hermeneutics. A summary of Beuchot's proposal is given, and then some of the developments made by other researchers are presented. Some of them are different proposals in their own right, as in the case of Samuel Arriarán's (Analogic-Baroque Hermeneutics) and Luis Álvarez Colín's (Symbolic-Analogic Hermeneutics). Some applications of Analogic Hermeneutics to several fields, such as Pedagogy, Psychology and Literature, are also mentioned.
\end{abstract}

Key words: philosophy in Mexico, interpretation, iconicity, symbol

\section{Introducción}

En este artículo me propongo dibujar en sus líneas principales lo que puede llamarse "movimiento" de la hermenéutica analógica, un movimiento joven y bastante reciente de la filosofía en México. En efecto, se trata del movimiento originado a partir de la obra de Mauricio Beuchot, filósofo mexicano que ha propuesto la hermenéutica analógica. Es de todos conocido que ahora, en la llamada tardomodernidad o posmodernidad, la hermenéutica es la episteme principal, el modo de conocimiento más extendido por obra de pensadores como Gadamer, Ricœur y Vattimo. Este último llama a la hermenéutica la koiné o lenguaje común de la posmodernidad. Digamos que la hermenéutica es el arte de la interpretación de textos; es un comprender lo que dice el texto, y un texto pueden ser muy diversas cosas, desde escritos, por supuesto, hasta acciones significativas, pasando por el diálogo, las obras de arte, etcétera.

En la tercera década del siglo xx, Heidegger puso de nuevo en circulación la hermenéutica, que había tomado de Dilthey; por eso se dice que lo que hizo en Ser y tiempo (1927) fue hermeneutizar la fenomenología de su 
maestro Husserl. Ésa fue la fenomenología hermenéutica, o la hermenéutica fenomenológica. Después, su discípulo Hans-Georg Gadamer planteó propiamente una hermenéutica filosófica y llegó incluso a universalizarla, esto es, a verla en todos los campos del saber, pero sobre todo en las ciencias humanas, tal como lo expone en su magna obra Verdad y método (1960). Otros pensadores han seguido por el camino de la hermenéutica desde otros enfoques, señaladamente Paul Ricœur, que la ha aplicado al estudio del símbolo, del mito y de la historia, como en Tiempo y narración (1985). O como Gianni Vattimo, discípulo y traductor de Gadamer, que ha dicho que estamos en el tiempo de la hermenéutica, y que ella debilitará la ontología para que no pueda ser ni rígida ni violenta, según lo expone, por ejemplo, en Más allá de la interpretación (1994). La hermenéutica avanza con autores como Maurizio Ferraris, quien ha escrito una célebre Historia de la hermenéutica (1998) que abarca hasta la actualidad, o Andrés OrtizOsés, que acaba de publicar Amor y sentido. Una hermenéutica simbólica (2003). En esta corriente de pensamiento se sitúa la aportación de Mauricio Beuchot, como veremos a continuación.

\section{La hermenéutica analógica}

Una vez que hemos visto qué es la hermenéutica, tratemos de explicitar el concepto de analogía para entender por qué se formula una hermenéutica analógica (seguiremos a Secretan 1975, que hace un recorrido histórico y una exposición sistemática de ese concepto). La analogía es un modo de significación o de predicación que se coloca entre la univocidad y la equivocidad; es, pues, algo tomado de la semántica o filosofía del lenguaje. El término unívoco tiene un significado idéntico para todos sus designados; es decir, se predica en un sentido igual respecto de todos sus posibles sujetos, como "hombre" o "mortal". En cambio, el término equívoco tiene significados completamente diferentes para todos sus designados; a saber, se predica de sus posibles sujetos en sentidos totalmente distintos, como "perro", significa de modo diferente e irreductible el animal, la constelación y el guardián celoso. En medio de ellos, el término análogo o analógico tiene algo de lo unívoco y algo de lo equívoco, si bien predomina esto último, ya que la semejanza tiene más de diferencia que de identidad; siempre vemos, por experiencia, que lo semejante a otra cosa es más diferente que idéntico a ella. Por eso, por encima de la identidad y la semejanza, en la analogía predomina la diferencia. La semejanza es sólo proporcional, aproximada; sin embargo, es suficiente para darnos conocimiento objetivo de las cosas que la poseen.

Trasladando estos conceptos, que provienen de la semántica y la retórica, Beuchot vio que la hermenéutica actual oscila entre los dos polos de la univocidad y la equivocidad, y que hace falta encontrar el equilibrio y 
la mediación de la analogía. Las hermenéuticas actuales, en su mayoría, o bien se colocan en el extremo del univocismo, como las de corte positivista - por ejemplo, la de Emilio Betti-, o bien en el del equivocismo, como la de Richard Rorty. La hermenéutica univocista sólo admite una interpretación para un texto; todas las demás tienen que ser falsas. Y es lo que vemos en los positivismos; por ejemplo, en el positivismo lógico, para el cual sólo había una interpretación válida del lenguaje adecuado a la realidad, a saber, el lenguaje perfecto o científico, planteado de diversas maneras por Russell y Carnap. Por el contrario, la hermenéutica equivocista es la que admite como interpretaciones válidas a casi todas, si no es que a todas, como se ve en los que hablan de una interpretación infinita (no en principio, sino de hecho) de la que surgen infinitas interpretaciones y entre las cuales, a la postre, no se puede decidir cuál es verdadera y cuál es falsa; ni siquiera tiene sentido hablar de verdad o falsedad en ella, como sucede con la hermenéutica planteada por Rorty y otros. Siendo estos extremos deplorables, porque llevaban al Escila del reduccionismo o al Caribdis de lo irreductible o lo inconmensurable, Beuchot vio que hacía falta plantear una hermenéutica que fuera analógica, es decir, que evitara los dos extremos: el de la única interpretación válida, como se daba en la hermenéutica univocista, y el de que son válidas todas las interpretaciones, según se concluía en la hermenéutica equivocista. Una hermenéutica analógica tenía que permitir más de una interpretación (contra el univocismo), pero no todas (contra el equivocismo), para evitar la desbandada de las interpretaciones, que era lo más frecuente o extendido. De hecho, Gadamer pone como modelo de la interpretación la frónesis aristotélica, que no es otra cosa que la analogía puesta en práctica; de modo que la interpretación gadameriana tiene una fuerte carga de analogicidad. También Ricœur alude a la analogía en varias partes de su obra; sobre todo últimamente, al hablar de uno mismo como otro, habla de la analogía de la acción — y no tanto de la analogía del sercomo algo que me permite interpretar los textos de otros con una aproximación y un distanciamiento que den cuenta de la subjetividad propia que se introduce en la interpretación, pero sin perder la objetividad alcanzable; hay también, en la hermenéutica ricœuriana, una fuerte carga de analogicidad.

Para lograr una interpretación bien situada, Beuchot propone recuperar para la hermenéutica los dos grandes modos de la analogía, planteados ya desde los pitagóricos y recibidos por Aristóteles y por muchos filósofos medievales: la analogía de atribución y la de proporcionalidad (Secretan 1975, pp. 19-28 y 40-47). La analogía de atribución se llama así porque, en ella, un predicado se atribuye a varios sujetos según una jerarquía de más propio a menos propio, como en el ejemplo aristotélico de "sano", que se predica más propiamente del organismo y menos propiamente del alimento, la medicina, el clima, etc. Hay, pues, un analogado principal y 
otros analogados secundarios, pero todos reciben la atribución, sólo que de forma diversa. Así, puede hablarse de varias interpretaciones posibles y válidas de un texto, pero según una gradación en la que habrá alguna que sea más apropiada y rica, y otras más alejadas y empobrecidas. La analogía de proporcionalidad, por su parte, es la que compara cosas como porciones en relación; esto es, muestra una relación compleja de porciones, y puede ser de proporcionalidad propia - como en "Los cimientos son a la casa lo que los pies al animal" o "El instinto es al animal lo que el intelecto al hombre"-, o de proporcionalidad impropia, cuando el significado es metafórico, y esto se da, por ejemplo, en "Las flores son al prado lo que la risa al hombre", que es lo que nos permite entender la metáfora "El prado ríe". Todos estos ejemplos son de Aristóteles. Al incorporar esos tipos de analogía, la hermenéutica tendría la posibilidad de evitar tanto el univocismo como el equivocismo y de beneficiarse de un modelo analógico de la interpretación.

Con estos razonamientos, Beuchot presentó una primera expresión de estas ideas en 1993, en una ponencia leída en el Congreso Nacional de Filosofía, que se llevó a cabo en la ciudad de Cuernavaca, México; allí mismo recibió las réplicas de Mariflor Aguilar, Ambrosio Velasco, Raúl Alcalá, Samuel Arriarán y José Manuel Orozco Garibay. El título de la ponencia era "Los márgenes de la interpretación: hacia un modelo analógico de la hermenéutica", y contenía una primera aproximación al tema (la ponencia y las réplicas fueron publicadas en Beuchot 1995 y en las memorias de ese congreso, a saber, Aguilar 1995).

Esta ponencia, muy ampliada, constituyó el capítulo nuclear del libro de Beuchot, Tratado de hermenéutica analógica. Hacia un nuevo modelo de interpretación (1997b). En él se exponen las ideas generales de una hermenéutica analógica, que ya hemos visto, y se trazan conexiones con la ontología, la ética y la teoría de la argumentación, sobre todo la retórica. Asimismo, para que sirvan de ejemplo, se hacen aplicaciones a varias disciplinas, como la filología y el psicoanálisis, y se aborda el arduo problema de la tradición y la innovación en hermenéutica.

Luego señaló Beuchot que la analogía de proporcionalidad impropia o figurada es la metáfora, mientras que la analogía de atribución y la de proporcionalidad propia pertenecen a un ámbito que se puede llamar de metonimia, según lo ha manejado él mismo. Esto permite una oscilación entre el sentido literal, que se acercaría a lo metonímico, y el sentido alegórico o simbólico, que entraría en el campo de lo metafórico. Según se necesitara, habría posibilidad de aplicar una interpretación más literal (aunque lo propiamente literal, como la univocidad, es sólo un ideal) o aplicar una interpretación más alegórica, según hiciera falta. Estas ideas surgieron a raíz de un interesante diálogo de Beuchot con el filósofo español Eugenio Trías acerca del libro de éste, La aventura del espíritu (1994), en el 
que afirma que el pensamiento medieval fue metafórico, mientras que el moderno fue metonímico. Beuchot mostró que la analogía abarca los dos modos del discurso (el metafórico y el metonímico) y que, por lo tanto, un pensamiento analógico puede jugar con esos dos polos, y los reúne en el límite, en un límite analógico; más que en un ser fronterizo, en un ser mestizo (cfr. Beuchot 1997a; puede verse la respuesta en Trías 1997).

Posteriormente, Beuchot encontró la idea de la analogía en Peirce, bajo la forma de la iconicidad (pues para Peirce lo icónico es analógico), y de alguna manera en Wittgenstein, con su teoría de los paradigmas y los parecidos de familia, y trató de incorporarlas a su propuesta en su libro Perfiles esenciales de la hermenéutica (1998), donde comenzó a hablar de una hermenéutica analógico-icónica. La analogía y la iconicidad peirceana iban ya de la mano, enriqueciendo la hermenéutica analógica en el aspecto semiótico, ya que el signo icónico es decisivo para comprender los procesos del pensamiento y para entablar comunicación.

Esa idea de la iconicidad, aplicada al símbolo, se ve en otro libro de Beuchot, Las caras del símbolo: ícono e ídolo (1999). Aquí señala un problema terminológico, porque el símbolo, que es el signo más rico, según autores como Cassirer y Ricœur, corresponde al ícono de Peirce; mientras que para éste, el símbolo es el signo arbitrario. Así, en la primera tríada en la que Peirce divide el signo -índice, ícono y símbolo-, el índice es el signo natural, el signo unívoco; el símbolo es el signo artificial o arbitrario, meramente convencional y, por lo mismo, sujeto a la equivocidad, equívoco; mientras que el ícono es el signo intermedio, análogo o analógico. Además, allí Beuchot contrapone el ícono, que es el lado bueno del símbolo, con el ídolo, que es su rostro malo, ya que el símbolo, cuando funciona como ícono, da lo que representa; mientras que, cuando funciona como ídolo, detiene en sí mismo, no deja pasar, no remite.

Asimismo, Beuchot ha hecho posteriormente una aplicación de la hermenéutica analógico-icónica en su libro Universalidad e individuo. La hermenéutica analógica en la filosofía de la cultura y las ciencias humanas (2002). Finalmente, en Hermenéutica analógica y del umbral (2003), señala una dependencia interesante respecto de Ricœur. Como es muy sabido, en su libro La metáfora viva (1975), Ricœur llega a plantear la interpretación de las metáforas como lo central de la hermenéutica. La interpretación tiene el modelo de la metáfora; es decir, se propone un modelo metafórico de la interpretación. A Beuchot esto le parece discutible, ya que, según hemos visto antes, la metáfora es el tipo de analogía más cercano a la equivocidad; de hecho, tiene el mayor peligro de caer en la equivocidad, o por lo menos se centra en el sentido alegórico y no nos basta para aproximarnos al sentido literal; por ello hay que acudir al polo metonímico de la interpretación, que complementa al polo metafórico. Jakobson fue quien le reveló a Beuchot que lo que une la metonimia y la metáfora es la analogía; 
por eso, en lugar de proponer una hermenéutica metonímica frente a la hermenéutica metafórica ricœuriana, Beuchot propuso una hermenéutica analógica; esto es, una hermenéutica que pudiera dar cuenta de los dos polos del discurso, según Jakobson, que son la metáfora y la metonimia. De esta manera podría abarcarlos a los dos y oscilar entre ellos según lo pidiera el texto, que requiere una interpretación a veces más metonímica y a veces más metafórica, según se trate del sentido literal o del alegórico.

La hermenéutica analógica, pues, nos ayuda de esa forma a aproximarnos al sentido literal cuando el texto así lo exige, y a disfrutar el sentido alegórico o simbólico cuando el texto lo permite. Eso nos da una hermenéutica abierta, pero lo suficientemente firme para alcanzar cierto rigor; es decir, reconoce la subjetividad de la interpretación, pero sin renunciar a toda objetividad, la cual se alcanza proporcionalmente, analógicamente. $\mathrm{Y}$ así nos previene contra las pretensiones reduccionistas del univocismo, pero también contra el relativismo irreductible del equivocismo, de las hermenéuticas equívocas que, por desgracia, son la mayoría en la actualidad.

\section{Profundizaciones y aplicaciones}

En el ámbito de las exposiciones, clarificaciones y profundizaciones, Enrique Aguayo Cruz, de la Universidad La Salle, de México, ha hecho una exposición sistematizada de la hermenéutica analógica (Aguayo 2001). Otra exposición general, pero con varias aplicaciones principales, ha sido hecha por mí (Conde 2001 y 2003), en la que se destacan aplicaciones a la psicología y al derecho. Pero la hermenéutica analógica reconoce que tiene una raigambre ontológica o metafísica muy profunda; por ello, su relación con la ontología la han estudiado César Peregrina Mancilla (2001) y el profesor argentino Juan José Herrera, de la Universidad del Norte Santo Tomás de Aquino, de Tucumán (Herrera 2003). También se ha profundizado su vinculación con la antropología filosófica en trabajos de Jesús María Herrera Aguilar (1999) y de Juan Pablo Martínez Hernández (2003). Algunos aspectos éticos de la hermenéutica analógica los ha abordado Remedios Álvarez Santos, del Tecnológico de Monterrey (Álvarez Santos 2003), sobre todo en lo que puede ofrecer ante éticas posmodernas. Y la profesora Dora Elvira García González ha examinado sus conexiones con la filosofía política y con la filosofía de la cultura (García González 2001), tratando de mostrar cómo puede integrar elementos del liberalismo y del comunitarismo. Se puede decir que todo esto abarca la construcción interna de la misma hermenéutica analógica; pero también, se ha aplicado en varios campos.

La hermenéutica analógica ha sido aplicada, por ejemplo, a la antropología científica o positiva por Sofía Reding Blase (Reding 1999), quien 
fue profesora en la Escuela Nacional de Antropología e Historia y ahora lo es del Tecnológico de Monterrey. Reding muestra cómo la hermenéutica analógica puede dar a la antropología y a la historia una comprensión a la vez más dúctil y objetiva de las otras culturas. Por su parte, al abordar el problema del multiculturalismo, Alejandro Salcedo usó la hermenéutica analógica como modelo de interpretación (Salcedo 2000) y también en comparación con otros modelos (Salcedo 2001). Además, se ha aplicado a la literatura; por ejemplo, en los trabajos de Caleb Olvera Romero, filósofo y poeta de Aguascalientes (Olvera 2000), quien encuentra una manera de introducir distinciones, que es lo que pide la analogía, para desentrañar el significado de las obras literarias. Nora Matamoros la ha aplicado al importante problema de la comunicación (Matamoros 2000), planteando cómo la analogicidad, según lo sostenía ya Husserl, es lo que rige mi comunicación con el otro, al que considero un álter ego. El profesor argentino Mario Silar, de la UNSTA de Buenos Aires, la ha vinculado con la semiótica (Silar 2001), y además la ha comparado con el pensamiento complejo de Edgar Morin. Por mi parte, la he aplicado al urbanismo y al turismo (Conde 2002), y me parece haber encontrado que la analogía nos puede llevar a una arquitectura más humana y a un empleo más humano del tiempo de ocio.

Víctor Hugo Méndez Aguirre, del Centro de Estudios Clásicos del Instituto de Investigaciones Filológicas (UNAM), ha empleado la hermenéutica analógica aplicándola con provecho a la filología clásica, y ha hecho muy interesantes lecturas de Platón y de Aristóteles desde esta perspectiva (Méndez 2002). Virginia Aspe Armella la ha aplicado en sus trabajos históricos sobre la filosofía novohispana, ya que muchos de los pensadores de esta época, como Bartolomé de las Casas, Bernardino de Sahagún y Alonso de la Vera Cruz emplearon un pensamiento analógico para entrar en contacto con las nuevas culturas, sin llevar una intención destructora, y para comprenderlas, al menos en parte (Aspe 2002). César Gordillo Pech ha aplicado la hermenéutica analógica al psicoanálisis; primero, en cuanto método de lectura de las obras de Freud (Gordillo 2002), y después, como instrumento interpretativo-clínico, en comparación con el que ofrecen otras escuelas psicoanalíticas (Gordillo 2003). Gordillo sostiene la tesis de que la hermenéutica analógica, utilizada en la clínica, puede ayudar al paciente desde su simbología propia sin imponerle actitudes, pero también sin dejarlo relativistamente al garete. Ricardo Mazón Fonseca ha hecho una profunda aplicación de nuestra hermenéutica al estudio del mito (Mazón 2002); allí ha mostrado cómo la analogía es, según decía ya el propio Kant, el mejor acceso (si no es que el único) a lo simbólico. Alejandro Martínez de la Rosa, de la Facultad de Ciencias Políticas de la UnAm, la ha empleado en los estudios político-sociales, concretamente en los movimientos latinoamericanos de liberación (Martínez de la Rosa 2003). Y, finalmente, Ali- 
cia Ocampo Jiménez (Ocampo 2003) la ha usado en los estudios de género, especialmente en el feminismo. Se empieza a ver que hace falta un feminismo analógico que supere las antinomias del clásico feminismo univocista, el cual conduce a la mujer a imitar al varón y, con ello, a darle la razón en los mismos errores que éste ha cometido, sin respetar las diferencias de género; y que también supere el feminismo equivocista, al que identifica con las feministas radicales, que conduce como revancha a una especie de opresión del varón y que, en el fondo, equivale a repetir la misma actitud que ha criticado y combatido. Un feminismo analógico respetaría y valoraría las diferencias propias de la mujer, pero reivindicando su igualdad en dignidad y derechos.

Como se ve, la hermenéutica analógica ha encontrado numerosas aplicaciones que han fomentado su uso y la han mejorado con ampliaciones y correcciones, resultado de esas experiencias más específicas y concretas. No obstante, también ha sido objeto de diversas discusiones que han sido muy enriquecedoras. Veremos algunas a continuación.

\section{Discusiones}

Una de las discusiones sobre la hermenéutica analógica y sus problemas fue dirigida por José Rubén Sanabria (1998), ya fallecido, en la que participaron, entre otros, Jorge Velázquez Delgado y María Rosa Palazón. Un autor que ha brindado objeciones muy certeras y una discusión constructiva ya muy extensa ha sido Raúl Alcalá Campos, de la UNAM; las problematizaciones de éste y las respuestas de Beuchot se han reunido en un volumen (Alcalá 1999). Otro volumen fue dirigido por Alberto Carrillo Canán, de la Universidad Autónoma de Puebla, donde participaron, entre otros, Nora María Matamoros y Jorge Luis Gardea Pichardo (Carrillo 1999). Una nueva discusión fue compilada por Manuel Velázquez y Miguel Ángel Sobrino, de la Universidad del Estado de México en Toluca (Sobrino y Velázquez 2000); en ella participaron, entre otros, Ana Berta Nova y Jesús Reyes Pérez. Otra más fue realizada en la Universidad Intercontinental y reunida en un volumen por Alejandro Gutiérrez Robles (Gutiérrez 2000), donde figuran, entre otros, Raúl Alcalá, Ambrosio Velasco y Pio Colonnello. Una más se hizo en la Universidad de Aguascalientes (Luján 2002) y la compiló Enrique Luján Salazar, con textos de José de Lira Bautista y Patricia Patiño Bahena, entre otros. Finalmente, hay otra, efectuada en la Facultad de Filosofía de la Universidad Michoacana, compilada por Víctor Hugo Valdés Pérez (Valdés 2002b), en la que participaron Rubí de María Gómez y Mauricio Coronado.

Guillermo Hurtado Pérez (Hurtado 2003a) recoge otra discusión en la que se incluyen textos de Victórico Muñoz Rosales y Juan Cordero Hernández, ambos de la UnAm. Puede verse una discusión sobre aplicaciones de la hermenéutica analógica al multiculturalismo en un volumen colectivo 
reunido por María Antonia González Valerio y Víctor Hugo Valdés Pérez (González Valerio y Valdés 2003), en el que participan autores como Dora Elvira García González y Alejandro Salcedo Aquino. También se ha discutido la aplicación de la hermenéutica analógica al psicoanálisis en un volumen colectivo compilado por Luis Álvarez Colín (2003), en el que destacan las críticas de Rosario Herrera y Marcela Madrid Gómez Tagle, así como las aplicaciones positivas de Felipe Flores y Fernanda Clavel.

\section{Ramificaciones: la hermenéutica analógico-barroca}

Algo muy importante ha sucedido: la hermenéutica analógica ha suscitado nuevas corrientes que han surgido de ella como ramas de un tronco. Esto ha enriquecido la filosofía mexicana, pues se ha tratado básicamente de productos que surgieron en nuestro país, como fruto de las aplicaciones y discusiones que acabamos de señalar. Trataremos de aproximarnos a las ramificaciones que se han constatado hasta ahora.

Uno de los que han aplicado y discutido la propuesta de Beuchot, Samuel Arriarán, profesor boliviano radicado en México, trabajó con un grupo en la Universidad Pedagógica Nacional, de México, las aplicaciones de la hermenéutica analógica a la educación, sobre todo multicultural. Arriarán estudiaba, asimismo, el concepto del barroco, a través principalmente de la obra de Bolívar Echeverría, ya que el ethos barroco fue paradigmático del multiculturalismo, a tal punto, que muchos teóricos veían en él la posmodernidad avant la lettre, o decían que la posmodernidad era el neobarroco.

Pero lo que se encontró fue que el barroco es eminentemente analógico y que sin la noción de analogía no se puede comprender bien. Esto lo llevó a combinar ambas ideas y a obtener una nueva propuesta, la hermenéutica analógico-barroca, que, en manos de Arriarán, se volvió muy fecunda. De hecho, hubo primero un libro de Arriarán en coautoría con el propio Beuchot, sobre la aplicación de la hermenéutica analógica a la educación (Arriarán y Beuchot 1999a), y luego otro, también de ambos, sobre la filosofía frente al multiculturalismo de esta época, llamada del neobarroco (Arriarán y Beuchot 1999b). Allí se planteaban los principios fundamentales de la aplicación de la hermenéutica analógica al estudio del barroco, y la proyección del ethos barroco al multiculturalismo, sobre todo en el neobarroco de la posmodernidad.

La línea de investigación de ese grupo de trabajo fue muy fructífera, y llevó a reflexiones y aplicaciones de la hermenéutica analógico-barroca a la educación. Pueden verse como resultados de ella diversas ponencias, artículos, tesis y un volumen colectivo (Arriarán y Hernández 2001). De este grupo, Elizabeth Hernández ha presentado una tesis de maestría (Hernández 2001) y Arturo Álvarez Balandra un libro (Álvarez Balandra 2002) sobre ejemplos específicos de esas aplicaciones. 


\section{Hermenéutica simbólico-analógica}

Otro investigador del grupo de Beuchot ha sido Luis Álvarez Colín, filósofo y psicólogo, dedicado a la academia y a la psicoterapia familiar. Él hizo varias aplicaciones de la hermenéutica analógica a la psicología y también formuló su propia propuesta: una hermenéutica simbólico-analógica que utiliza la analogía como instrumento para interpretar los símbolos, sobre todo los símbolos que se dan en la interacción de la familia.

Los primeros trabajos de Álvarez Colín fueron de aplicación de la hermenéutica analógica a la comunicación y la psicología, y al símbolo como elemento psicológico individual y social, principalmente en el multiculturalismo latinoamericano (Álvarez Colín 2000). A partir de ello surgió la hermenéutica simbólico-analógica, que se utilizó para dar relieve a los símbolos que hay en la vida familiar, pues, como dice este autor, en la familia, antes que historia, hay mitos, y antes que procesos comunitarios, hay ritos. Todo ello implica simbolicidad, y el símbolo requiere la analogicidad para ser interpretado (Álvarez Colín 2002).

En su propuesta, Álvarez Colín plantea la familia como una configuración hermenéutico-analógica de ilusiones, símbolos, mitos y rituales; introduce entonces una hermenéutica simbólico-analógica al destacar la mutua pertenencia del símbolo y la analogía, de modo que la metafísica del signo conduce a la integración símbolo-analogía en la hermenéutica psicológica. Eso le muestra el fundamento antropológico de la familia, muy centrado en el símbolo; para penetrar en él se necesita un instrumento interpretativo adecuado que pueda conjuntar símbolo y analogía con el fin de adentrarse en la familia como configuración creativa de símbolos. Llegar a esos símbolos será fuente de fortalecimiento, curación y transformación de las relaciones familiares. Por lo demás, Álvarez Colín ha hecho nuevos desarrollos de su propuesta en un volumen de estudios de aplicación de la hermenéutica al psicoanálisis que él ha compilado (Álvarez Colín 2003, pp. 193-261).

\section{Hermenéutica del equilibrio pulsional}

En esa misma línea de la psicología, concretamente del psicoanálisis, ha surgido, por parte de Víctor Hugo Valdés Pérez, de la Facultad de Filosofía de la Universidad Michoacana, y del Instituto de Psicoanálisis de Morelia, la hermenéutica del equilibrio pulsional. Según él, ésta es una aplicación de la hermenéutica analógica a la labor psicoanalítica (Valdés 2002a).

Valdés Pérez plantea la educación de las pulsiones, de modo que, en lugar de ser reprimidas o desbocadas, encuentren, más allá de la sublimación, su cauce conveniente. A través del análisis de la cultura, encuentra que una postura univocista frente a la misma promovería la aceptación y el 
rendimiento, con la inhibición o represión, lo cual conduce a la patología; en cambio, una postura equivocista llamaría a dar rienda suelta a la satisfacción de pulsiones y deseos, lo cual es también otra suerte de patología; a diferencia de ellas, una postura analogicista propone un encauzamiento o educación en la línea del equilibrio o proporción, que es la analogía misma, y que está en lo que el propio Freud llama (en el § II de El malestar en la cultura) "el arte de vivir".

\section{Iusnaturalismo histórico-analógico}

En la línea de la filosofía del derecho, concretamente, de la fundamentación filosófica de los derechos humanos, ha surgido el iusnaturalismo histórico-analógico de Jesús Antonio de la Torre Rangel, jurista y filósofo de la Universidad de Aguascalientes. Ya de suyo, este autor había aplicado la hermenéutica analógica a diversos temas de la iusfilosofía (Torre 1998); pero en su propuesta de un iusnaturalismo histórico-analógico va más allá (Torre 2001).

Torre Rangel trata de fundamentar los derechos humanos tanto en la naturaleza del hombre como en su historia, o en una naturaleza dada históricamente, de modo que tenga, analógicamente, el afianzamiento de algo natural y el dinamismo de lo histórico. La analogicidad servirá para historizar la naturaleza humana, pero también para que no se pierda la dimensión ontológica de dicha naturaleza por su estar en la historia. Allí cobran un nuevo sentido los derechos humanos, como algo que está enraizado en la naturaleza del hombre, pero que se desenvuelve históricamente en el proceso que ésta sigue en su existencia concreta, individual y social.

\section{Hermenéutica analógico-crítica}

El profesor Francisco Arenas-Dolz, de la Universidad de Valencia, pertenece al grupo de Adela Cortina y Jesús Conill, que promueven una hermenéutica crítica. Él ha realizado un entrecruzamiento de esta corriente con la hermenéutica analógica, con lo que se produjo una hermenéutica analógicocrítica (Arenas-Dolz 2003). Mientras que la hermenéutica crítica de Cortina y Conill efectúa una crítica de las instituciones políticas, una hermenéutica analógico-crítica es más radical y hace la crítica de la cultura, pero tratando de proponer soluciones y salidas.

\section{Hermenéutica analógica de la pedagogía de lo cotidiano}

Luis Eduardo Primero Rivas, filósofo y educador de la Universidad Pedagógica Nacional, ha trabajado la pedagogía de lo cotidiano, en la línea de la sociología de lo cotidiano de Agnes Heller (Primero 2000, 1999 y 
2002). Con su grupo, trabajó la aplicación de la hermenéutica analógica a esa perspectiva que él ya desarrollaba, y propulsa ahora la hermenéutica analógica de la pedagogía de lo cotidiano. Ha escrito un libro en coautoría con Beuchot (Beuchot y Primero 2003), en el que se explicitan los vínculos y las perspectivas que esta propuesta puede tener en la pedagogía.

\section{La referencia analógica}

Finalmente, uno de los últimos avances en la línea de la hermenéutica analógica es la aportación de María Antonia González Valerio, que ha estado trabajando la noción de referente analógico. Partiendo de Gadamer y de Ricœur, nos hace ver que la idea de mimesis sólo puede aplicarse al arte y la estética si se entiende con un referente no unívoco, tampoco equívoco, sino analógico. De esta manera, la mimesis no es una copia, sino una imagen realizada en el arte. La referencia que se da en la literatura sólo puede ser analógica, pues así es como se le quita el carácter representacionista y se abre a una mayor creatividad. Pero no sólo ha aplicado esta idea de referente analógico a la literatura de ficción (González Valerio, en prensa), sino que también ahora la está aplicando a la historia, esto es, al relato histórico.

\section{Conclusión}

Como se ve, el movimiento de la hermenéutica analógica ha crecido y marcha pujante. Se sigue construyendo internamente, y se sigue aplicando al exterior. La misma aplicación a diversos campos del conocimiento muestra que su estructura teórica se está construyendo adecuadamente, o, por lo menos, que está siendo fructífera. Pero lo más importante es que acepta y aprovecha las críticas, las cuales contribuyen a ambos fines: su construcción interna y su aplicación externa. La crítica misma ha producido las ampliaciones y desarrollos como ramas surgidas de ese tronco en crecimiento. Esta feracidad hacia dentro y hacia fuera, en construcciones, discusiones, aplicaciones y nuevas propuestas que surgen de ella, muestra que la hermenéutica analógica de Beuchot ha dado buenos frutos.

Se ha dicho que la hermenéutica analógica es uno de los principales movimientos en el panorama filosófico de México, que ha suscitado gran discusión y diálogo en nuestros medios (Hurtado 2003b, p. 75). Poco a poco va aumentando su recepción en América Latina (Colombia y Argentina) y en España. Lo que en definitiva se propone es colaborar en la labor filosófica de Iberoamérica, en esta época tan turbulenta, llena de escepticismo, relativismo y confusión, pues, en efecto, la hermenéutica analógica desde sus inicios ha intentado reducir todo el equivocismo que nos rodea 
en forma de relativismo, escepticismo e incluso nihilismo, pero sin caer en el tan rechazado univocismo (racionalismo, cientificismo, positivismo). La hermenéutica analógica busca abrir puertas en el impasse de la discusión actual y del que ya muchos nos hemos cansado. Resulta, así, como un respiro y una alternativa para seguir en el camino de la filosofía.

\section{BIBLIOGRAFÍA}

A. Obras de Mauricio Beuchot sobre hermenéutica analógica

Beuchot, Mauricio, 2003, Hermenéutica analógica y del umbral, San Esteban, Salamanca (España).

—_, 2002, Universalidad e individuo. La hermenéutica analógica en la filosofía de la cultura y en las ciencias humanas, Jitanjáfora, Morelia.

—_, 1999, Las caras del símbolo: ícono e ídolo, Caparrós Editores, Madrid (Esprit).

__ 1998, Perfiles esenciales de la hermenéutica, UnAm, México; 2a. ed., 2000; 3a. ed., 2002.

—_ 1997a, "Eugenio Trías y Hermes: límites, analogía y mestizaje", en Sanabria y Beuchot 1997, pp. 271-288.

__ 1997b, Tratado de hermenéutica analógica. Hacia un nuevo modelo de interpretación, UnAm, México; 2a. ed., UnAm/Ítaca, México, 2000.

- 1995, Los márgenes de la interpretación: hacia un modelo analógico de la hermenéutica, Universidad Iberoamericana, México. También en Aguilar 1995, pp. 177-182.

Arriarán, Samuel y Mauricio Beuchot, 1999a, Virtudes, valores y educación moral. Contra el paradigma neoliberal, Universidad Pedagógica Nacional, México.

—_, 1999b, Filosofía, neobarroco y multiculturalismo, Ítaca, México.

Beuchot, Mauricio y Luis Eduardo Primero Rivas, 2003, La hermenéutica analógica de la pedagogía de lo cotidiano, Primero Editores, México.

B. Bibliografía sobre la hermenéutica analógica de Mauricio Beuchot

Aguayo, Enrique, 2001, La hermenéutica filosófica de Mauricio Beuchot, Ducere, México.

Alcalá Campos, Raúl, 1999, Hermenéutica, analogía y significado. Discusión con Mauricio Beuchot, Surge, México.

Álvarez Balandra, Arturo Cristóbal, 2002, Hermenéutica analógica y procesos educativos, número especial de Analogía (México), no. 10.

Álvarez Colín, Luis (comp.), 2003, Hermenéutica analógica, símbolo y psicoanálisis, Ducere, México.

__ 2002, El universo simbólico de la familia. Un estudio de psicología hermenéutica, Ducere, México.

——, 2000, Hermenéutica analógica, símbolo y acción humana, Torres Asociados, México (Hermenéutica, Analogía e Imagen).

Álvarez Santos, Remedios, 2003, Hermenéutica analógica y ética, Torres Asociados, México.

Arenas-Dolz, Francisco, 2003, Hacia una hermenéutica analógico-crítica, número especial de Analogía Filosófica (México), no. 12. 
Arriarán, Samuel y Elizabeth Hernández (comps.), 2001, Hermenéutica analógicobarroca y educación, Universidad Pedagógica Nacional, México.

Aspe Armella, Virginia, 2002, Las aporías fundamentales del periodo novohispano, conaculta, México (Sello Bermejo).

Carrillo Canán, Alberto (comp.), 1999, Hermenéutica, analogía y diálogo intercultural, CONACYT/Benemérita Universidad Autónoma de Puebla, México.

Conde Gaxiola, Napoleón, 2003, Hermenéutica analógica, humanismo e historia, Primero Editores, México.

—_, 2002, Dos aplicaciones de la hermenéutica analógica: el urbanismo y el turismo, Torres Asociados, México.

——, 2001, Hermenéutica analógica. Definición y aplicaciones, Primero Editores, México.

García González, Dora Elvira, 2001, Hermenéutica analógica, política y cultura, Ducere, México.

González Valerio, María Antonia, en prensa, "Consideraciones sobre la hermenéutica analógica”, en VII Jornadas de Hermenéutica, UNAM, México.

González Valerio, María Antonia y Víctor Hugo Valdés Pérez (comps.), 2003, Hermenéutica analógica y pluralidad cultural, Nous Ediciones, Morelia.

Gordillo Pech, César, 2003, Tiempo, analogía lingüística y significación. Antecedentes y perspectiva de la historicidad en la técnica psicoanalítica, Primero Editores, México.

—_, 2002, Hermenéutica analógica, psicoanálisis y lenguaje. Prolegómenos a la aporía de la técnica de interpretación, número especial de Analogía Filosófica (México), no. 11.

Gutiérrez Robles, Alejandro (comp.), 2000, La hermenéutica analógica: hacia un nuevo orden de racionalidad. Círculo de Hermenéutica/Diálogos con Mauricio Beuchot, Universidad Intercontinental/Plaza y Valdés, México.

Hernández Alvídrez, Elizabeth, 2001, Hermenéutica, educación y analogía. Fundamentos hermenéuticos de una educación mediante la lectura de textos literarios, tesis de maestría en Filosofía de la Cultura, Universidad Michoacana/Universidad Intercontinental, México.

Herrera, Juan José, 2003, Hermenéutica, analogía y ontología en Mauricio Beuchot, Nous Ediciones, Morelia.

Herrera Aguilar, Jesús María, 1999, Antropología filosófica y analogía en Mauricio Beuchot, número especial de Analogía Fílosófica (México), no. 5.

Hurtado Pérez, Guillermo (comp.), 2003a, Hermenéutica analógica. Aproximaciones y elaboraciones, Ducere, México.

Luján Salazar, Enrique (comp.), 2002, Hermenéutica analógica: una propuesta contemporánea. Diálogos con Mauricio Beuchot, Universidad Autónoma de Aguascalientes, Aguascalientes.

Martínez de la Rosa, Alejandro, 2003, La hermenéutica analógica y la emancipación de América Latina, Torres Asociados, México.

Martínez Hernández, Juan Pablo, 2003, Antropología filosófica en Mauricio Beuchot, Nous Ediciones, Morelia.

Matamoros Franco, Nora María, 2000, Hermenéutica analógica, comunicación y empatía, número especial de Analogía Filosófica (México), no. 7. 
Mazón Fonseca, Ricardo, 2002, La hermenéutica analógica y el mito, Primero Editores, México.

Méndez Aguirre, Víctor Hugo, 2002, ¿Filantropía divina en la ética de Aristóteles? Lectura desde la hermenéutica analógica, UNAM, México.

Ocampo Jiménez, Alicia, 2003, La hermenéutica analógica en el análisis de los feminismos en la postmodernidad, número especial de Analogía Filosófica (México), no. 13.

Olvera Romero, Caleb, 2000, Hermenéutica analógica y literatura, Primero Editores/AC Editores, México/Cali.

Peregrina Mancilla, César, 2001, La hermenéutica analógica y su fundamentación ontológica en Mauricio Beuchot, número especial de Analogía Filosófica (México), no. 9.

Reding Blase, Sofía, 1999, Antropología y analogía, Taller Abierto, México.

Salcedo Aquino, Alejandro, 2001, Multiculturalismo: orientaciones filosóficas para una argumentación pluralista, UNAM/Plaza y Valdés, México.

— 2000 , Hermenéutica analógica, pluralismo cultural y subjetividad, Torres Asociados, México.

Sanabria, José Rubén (comp.), 1998, Diálogos con Mauricio Beuchot sobre la analogía, Universidad Iberoamericana, México.

Silar, Mario, 2001, Hermenéutica analógica y semiótica en Mauricio Beuchot: un encuentro fecundo, número especial de Analogía Filosófica (México), no. 8.

Sobrino Ordóñez, Miguel Ángel y Manuel Velázquez Mejía (comps.), 2000, Analogía e interpretación filosófica, Universidad Autónoma del Estado de México-CICSYH, Toluca.

Torre Rangel, Jesús Antonio de la, 2001, Derechos humanos desde el iusnaturalismo histórico analógico, Porrúa/Universidad Autónoma de Aguascalientes, México.

—_ 1998, "Racionalidad analógica: un modo de acceso al iusnaturalismo histórico", Revista de Investigaciones Jurídicas (Escuela Libre de Derecho, México), vol. 22, pp. 411-428; también en Aurelia Vargas (comp.), 2000, Derechos humanos, filosofía y naturaleza, UNAM, México, pp. 37-54.

Valdés Pérez, Víctor Hugo, 2002a, Cultura y psicoanálisis. Hermenéutica del concepto de cultura en Freud, Nous Ediciones, Morelia.

- (comp.), 2002b, Hermenéutica analógica y filosofía de la cultura, Nous Ediciones, Morelia.

\section{Bibliogafía general}

Aguilar, Mariflor (comp.), 1995, Diálogos sobre filosofía contemporánea, UNAM, México.

Hurtado Pérez, Guillermo, 2003b, "Filosofía en México y filosofía mexicana", Logos (Universidad La Salle de México), vol. 31, no. 92, pp. 69-77.

Primero Rivas, Luis Eduardo, 2002, Epistemología y metodología de la pedagogía de lo cotidiano, Primero Editores, México.

—_, 2000, ¿Cuál Agnes Heller? Introducción a la obra de la filósofa húngara, Primero Editores/AC Editores, México/Cali.

— 1999 , Emergencia de la pedagogía de lo cotidiano, Primero Editores/AC Editores, México/Cali.

Secretan, Philibert, 1975, L'Analogie, Presses Universitaires de France, París. 
Sanabria, José Rubén y Mauricio Beuchot (comps.), 1997, Algunas perspectivas de la filosofía actual en México, Universidad Iberoamericana, México.

Trías, Eugenio, 1997, "Metonimia y modernidad (réplica a Mauricio Beuchot)", en Sanabria y Beuchot 1997, pp. 289-291.

Recibido el 14 de enero de 2004; aceptado el 27 de enero de 2004. 